\title{
Comparison of Neointimal Coverage of Sirolimus-Eluting Stents and Paclitaxel-Eluting Stents Using Optical Coherence Tomography at 9 Months After Implantation
}

\author{
Jin-Sun Kim, MD; Jung-Sun Kim, MD, PhD; Tae Hoon Kim, MD; Chunyu Fan, MD; \\ Jung Myung Lee, MD; Woong Kim, MD*; Young-Guk Ko, MD; Donghoon Choi, MD, PhD; \\ Myeong-Ki Hong, MD, PhD; Yangsoo Jang, MD, PhD
}

\begin{abstract}
Background: The differences between using Sirolimus-eluting stents (SESs) and Paclitaxel-eluting stents (PESs) in the vascular response at 9 months after implantation were examined with optical coherence tomography (OCT).
\end{abstract}

\begin{abstract}
Methods and Results: OCT was carried out in 33 SESs [33 patients, 19 with acute coronary syndrome (ACS) and 14 with stable angina pectoris (SAP)] and 27 PESs (27 patients, 15 with ACS and 12 with SAP) at 9 months after stent implantation. Stent strut coverage and apposition at each strut were evaluated. The frequency of uncovered struts was significantly higher in SES $(12.5 \pm 15.2$ vs $4.9 \pm 7.9 \%, P=0.01)$. The incidence of complete covered stents with neointima was $9.1 \%(3 / 33)$ in SES and $29.6 \%(8 / 27)$ in PES $(P=0.05)$. The pattern of neointima in PES was more heterogeneous than that in SES $(1.3 \pm 0.5$ for SES vs $2.0 \pm 0.6$ for PES, $P<0.001)$. The intracoronary thrombus was frequently detected in SES [10 (30.3\%) in SES vs $5(18.5 \%)$ in PES, $P=0.29]$.
\end{abstract}

Conclusions: Uncovered struts were frequently observed in SES, but the pattern of neointima was more heterogeneous in PES at 9 months. In addition, stent coverage was incomplete in both stent groups at 9 months after stent implantation. (Circ J 2010; 74: 320-326)

Key Words: Drug-eluting stent; Optical coherence; Paclitaxel; Sirolimus; Tomography

C ompared with previous bare-metal stents, drugeluting stents (DESs) significantly reduced restenosis but increased the concern for stent thrombosis, which is why $>1$ year of dual anti-platelet therapy (DAT) is currently recommended for DES-implanted patients. ${ }^{1}$ However, there is still considerable debate about the optimal duration of DAT because there are a number of different DESs currently being used. The differences in eluted drugs and their releasing patterns cause variable degrees of stent restenosis and neointimal coverage..$^{2-4}$ For example, rabbits that received various DESs for 14 or 28 days revealed varying rates of endothelial coverage by scanning electron microscopy according to the type of DES used..$^{5}$ Recent autopsy data from a registry totaling 81 human autopsies demonstrated that the most powerful histological predictor of stent thrombosis was endothelial coverage. The best morphometric predictor of late stent thrombosis (LST) was the ratio of uncovered struts to the total number of stent struts. ${ }^{6}$ Therefore, detection of neointima could be crucial in evaluating the risk of LST in clinical situations.
Optical coherence tomography (OCT) is a light-based imaging modality, using near-infrared light. The most valuable advantage of OCT is its high resolution, which is about 10 times better than conventional intravascular ultrasound (IVUS). ${ }^{7}$ For this reason, OCT is assessed as a better imaging modality than IVUS to evaluate vascular healing after stent implantation. ${ }^{8-12}$ Because of this advantage in resolution, we compared stent strut coverage and malapposition in Sirolimus-eluting stents (SESs) and Paclitaxel-eluting stents (PESs) using OCT.

\section{Methods}

\section{Study Population}

Ninety-three consecutive patients underwent a 9-month follow-up OCT examination between September 2007 and July 2008 and had been enrolled in the Yonsei OCT registry of the Severance Cardiovascular Hospital, Yonsei University College of Medicine, Korea. Among them, 60 patients [mean age $60.2 \pm 9.0$ years, 42 men $(70.0 \%)$ ] who had been treated

Received July 28, 2009; revised manuscript received October 15, 2009; accepted October 20, 2009; released online December 17, 2009 Time for primary review: 22 days

Division of Cardiology, Severance Cardiovascular Hospital, Yonsei University College of Medicine, Seoul, *Division of Cardiology, Inje University Busan Paik Hospital, Busan, South Korea

Mailing address: Jung-Sun, Kim, MD, Division of Cardiology, Severance Cardiovascular Hospital, Yonsei University College of Medicine, 120-752, Shinchondong, Seodaemun-gu, Seoul, South Korea. E-mail: kjs1218@yuhs.ac

ISSN-1346-9843 doi:10.1253/circj.CJ-09-0546

All rights are reserved to the Japanese Circulation Society. For permissions, please e-mail: cj@j-circ.or.jp 


\begin{tabular}{lccc|}
\hline Table 1. Baseline Characteristics & & & \\
& SES $(\mathbf{n}=\mathbf{3 3})$ & PES $(\mathbf{n}=\mathbf{2 7})$ & P-value \\
Age (years) & $59.4 \pm 8.7$ & $61.2 \pm 9.4$ & 0.47 \\
Male, $\mathrm{n}(\%)$ & $23(69.7 \%)$ & $19(70.4 \%)$ & 0.96 \\
Follow-up duration (days) & $271 \pm 44$ & $276 \pm 48$ & 0.63 \\
Hypertension, $\mathrm{n}(\%)$ & $12(36.4 \%)$ & $13(48.1 \%)$ & 0.36 \\
Diabetes mellitus, $\mathrm{n}(\%)$ & $11(33.3 \%)$ & $6(22.2 \%)$ & 0.34 \\
Hyperlipidemia, $\mathrm{n}(\%)$ & $14(42.3 \%)$ & $13(48.1 \%)$ & 0.66 \\
Smoking, $\mathrm{n}(\%)$ & $10(30.3 \%)$ & $5(18.5 \%)$ & 0.07 \\
Previous MI, $\mathrm{n}(\%)$ & $3(9.1 \%)$ & $2(7.4 \%)$ & 0.81 \\
ACS, $\mathrm{n}(\%)$ & $19(57.6 \%)$ & $15(55.6 \%)$ & 0.88 \\
Fasting glucose (mg/dl) & $113 \pm 39$ & $110 \pm 25$ & 0.72 \\
hsCRP (mg/L) & $7.1 \pm 15.4$ & $11.9 \pm 36.9$ & 0.52 \\
Total cholesterol (mg/dl) & $156 \pm 34$ & $162 \pm 48$ & 0.58 \\
LDL-cholesterol (mg/dl) & $94 \pm 32$ & $96 \pm 36$ & 0.88 \\
HDL-cholesterol (mg/dl) & $45 \pm 7$ & $46 \pm 10$ & 0.88 \\
Triglyceride (mg/dl) & $115 \pm 54$ & $105 \pm 48$ & 0.47 \\
\hline
\end{tabular}

SES, Sirolimus-eluting stent; PES, Paclitaxel-eluting stent; MI, myocardial infarction; ACS, acute coronary syndrome; hsCPR, high sensitivity C-reactive protein; LDL, low-density lipoprotein; HDL, high-density lipoprotein.

with SES (Cypher Select ${ }^{\circledR}$, Cordis, Miami Lakes, FL, USA) or PES (Taxus Liberte ${ }^{\mathrm{TM}}$, Boston Scientific, Natick, MA, USA) before $9( \pm 2)$ months were enrolled in this study. Thirty-three patients were excluded ( 26 were treated with other DESs, 5 had in-stent restenosis and 2 had poor OCT image quality). The DES was chosen by the operator. The exclusion criteria of this study were as follows: (1) untreated significant left main coronary artery disease; (2) in-stent restenosis ( $\geq 50 \%$ luminal diameter stenosis at 9 months); (3) apparent congestive heart failure or low ejection fraction $(\leq 35 \%)$; (4) renal insufficiency with baseline creatinine $\geq 2.0 \mathrm{mg} / \mathrm{dl}$; (5) unsuitable lesions for OCT procedure (vessel size $\geq 3.5 \mathrm{~mm}$ or proximal lesion at $10 \mathrm{~mm}$ from ostium of each artery); and (6) overlapping stent or bifurcation of artery. The study protocol was approved by the institutional ethics committee of Yonsei University College of Medicine and written consent was obtained from all patients before the procedure. After successful intervention, aspirin $(100 \mathrm{mg}$ ) and clopidogrel $(75 \mathrm{mg}$ ) were continuously administered for at least 9 months.

\section{Angiographic Analysis}

The lesion was classified morphologically according to American Heart Association/American College of Cardiology (AHA/ACC) standards. Quantitative coronary angiography analysis was performed using the computer-assisted automated edge detection method (CASS System II, Pie Medical Imaging, The Netherlands) by a single individual who was blinded to the patient's information and the type of stents used. The reference vessel diameter, minimal luminal diameter of the treated segment, percentage of diameter stenosis and lesion length were measured in the view that was the most severe and not foreshortened. Baseline and follow-up angiograms were evaluated in a similar manner.

\section{OCT Examination}

OCT was performed at $9( \pm 2)$ months after stent implantation. The OCT system used in this study consisted of a computer, a monitor display, an interface unit (Model M2 Cardiology Imaging System, LightLab Imaging, Inc, Westford, MA, USA) and a 0.014-inch wire-type imaging catheter (ImageWire, LightLab Imaging, Inc, Westford, MA,
USA). A motorized pull-back system at $1 \mathrm{~mm} / \mathrm{s}$ was used. A 6-Fr or 7-Fr guiding catheter was introduced into the coronary artery using a transradial or femoral approach. To remove the blood cells from the field of view, an occlusion balloon catheter (Helios, Avantec Vascular Corp, Sunnyvale, CA, USA), an over-the-wire type with the flush lumen and lumen for crossing the imaging catheter, was used. During image acquisition, the occlusion balloon was inflated to 0.4$0.6 \mathrm{~atm}$ and Ringer lactate was infused at 0.5 to $1.0 \mathrm{ml} / \mathrm{s}$. The image wire was pulled from distal to proximal, and continuous images were stored digitally for subsequent analysis.

\section{OCT Analysis}

OCT analysis was performed independently by 2 individuals who were blinded to the patient's information and the type of stents used. Cross-sectional OCT images were analyzed at 1-mm intervals (every 15 frames). For neointimal hyperplasia (NIH) thickness, the distance between the endo-luminal surface of the strut reflection and the vessel wall was measured by prolonging and joining the contours of the wall on either side of the strut shadow with a measurement line as perpendicular as possible to the strut and vessel wall. ${ }^{11,13} \mathrm{NIH}$ thickness inside every strut was measured and when there was no definite neointima over the stent strut, it was defined as an uncovered strut. ${ }^{13}$ The stent and lumen areas were measured by manual trace and the percentage of the NIH area was calculated as: NIH area $(\%)=([$ stent area-lumen area]/stent area) $\times 100$. When the strut was not fully attached to the vessel wall by visual estimation, the position of the stent strut to the vessel wall was measured by magnifying the individual stent strut to maximize accuracy. Stent malapposition was defined as struts that were detached from the vessel wall $\geq 160 \mu \mathrm{m}$ for SES and $\geq 130 \mu \mathrm{m}$ for PES regarding the differences in thickness of metal strut and polymer. ${ }^{14,15}$

The degree of NIH was divided into 4 grades: grade 0 , uncovered strut to total stent struts; grade 1, NIH thickness $<100 \mu \mathrm{m}$, which was not detected with IVUS; grade 2, NIH thickness between 100 and $200 \mu \mathrm{m}$, which was between the minimal thickness detectable using OCT and the minimal mean thickness in BMS; and grade 3, NIH thickness over $200 \mu \mathrm{m} .{ }^{16}$ The grade was determined as minimal and maximal grades including $\geq 10 \%$ of stent struts at each stent. 


\begin{tabular}{|c|c|c|c|}
\hline & SES $(n=33)$ & PES $(n=27)$ & P-value \\
\hline Target vessel & & & 0.90 \\
\hline LAD, n (\%) & $16(48.5 \%)$ & $14(51.1 \%)$ & \\
\hline LCX, n (\%) & $8(24.2 \%)$ & $7(25.9 \%)$ & \\
\hline $\mathrm{RCA}, \mathrm{n}(\%)$ & $9(27.3 \%)$ & $6(22.2 \%)$ & \\
\hline Lesion type B2 or C, $\mathbf{n}(\%)$ & $25(75.7 \%)$ & $21(77.8 \%)$ & 0.91 \\
\hline Stent diameter $(\mathrm{mm})$ & $2.9 \pm 0.3$ & $3.0 \pm 0.3$ & 0.21 \\
\hline Stent length (mm) & $24.6 \pm 7.0$ & $26.5 \pm 7.2$ & 0.32 \\
\hline Balloon to artery ratio & $1.1 \pm 0.1$ & $1.1 \pm 0.2$ & 0.92 \\
\hline Maximal pressure (atm) & $16.1 \pm 2.8$ & $15.4 \pm 1.9$ & 0.73 \\
\hline \multicolumn{4}{|l|}{ Pre-intervention QCA data } \\
\hline Mean RVD (mm) & $2.7 \pm 0.4$ & $2.8 \pm 0.4$ & 0.38 \\
\hline MLD (mm) & $0.7 \pm 0.4$ & $0.7 \pm 0.5$ & 0.71 \\
\hline$\%$ DS & $75.5 \pm 14.6$ & $75.0 \pm 16.0$ & 0.90 \\
\hline \multicolumn{4}{|l|}{ Post-intervention QCA data } \\
\hline Mean RVD & $2.8 \pm 0.4$ & $2.9 \pm 0.4$ & 0.17 \\
\hline MLD (mm) & $2.6 \pm 0.4$ & $2.8 \pm 0.4$ & 0.07 \\
\hline$\%$ DS & $6.0 \pm 7.4$ & $3.7 \pm 7.9$ & 0.25 \\
\hline Acute gain $(\mathrm{mm})$ & $1.9 \pm 0.5$ & $2.1 \pm 0.5$ & 0.25 \\
\hline \multicolumn{4}{|l|}{ 9-month follow-up QCA data } \\
\hline Mean RVD & $2.7 \pm 0.4$ & $2.8 \pm 0.3$ & 0.43 \\
\hline MLD (mm) & $2.5 \pm 0.4$ & $2.3 \pm 0.5$ & 0.09 \\
\hline$\%$ DS & $6.6 \pm 10.6$ & $16.1 \pm 14.3$ & 0.004 \\
\hline Late loss (mm) & $0.1 \pm 0.4$ & $0.5 \pm 0.4$ & 0.001 \\
\hline
\end{tabular}

SES, Sirolimus-eluting stent; PES, Paclitaxel-eluting stent; LAD, left anterior descending coronary artery; LCX, left circumflex coronary artery; RCA, right coronary artery; QCA, quantitative coronary angiography; RVD, reference vessel diameter; MLD, minimal lesion diameter; DS, diameter stenosis.

The heterogeneity score of NIH thickness was generated by subtracting the minimal grade from the maximal grade.

Cross sections with uncovered or malapposed struts were defined if $\geq 1$ stent strut was uncovered or malapposed on the cross section, and cross sections with an uncovered strut ratio $>0.3$ was defined when the ratio of uncovered struts to total stent struts per cross section was more than $0.3 .^{6}$ Thrombi were defined as signal-rich, low-backscattering protrusions or high-backscattering protrusions inside the lumen of the artery with signal-free shadowing on the OCT image. ${ }^{17}$

\section{Statistical Analysis}

Results are expressed as a mean \pm SD or $\mathrm{n}(\%)$. Comparisons of categorical variables were made using the chi-squared test or Fisher's exact test while Student's t-test was used for comparing continuous variables. If the distributions were skewed, a non-parametric test was used. Inter-observer and intra-observer variability in the measured distance and area were assessed by evaluation of 20 random cross-sectional images in our laboratory. ${ }^{18}$ The variations between measurements were calculated using the linear mixed model (oneway mixed and two-way mixed models). All analyses were performed using Statistical Analysis Systems (SAS) software (SAS; 9.1.3., SAS Institute, Cary, NC, USA). A Pvalue $<0.05$ was considered statistically significant.

\section{Results}

\section{Baseline Characteristics}

A total of 60 patients who were implanted with either SESs or PESs underwent OCT. The mean follow-up duration from PCI to OCT was $273 \pm 46$ days ( $271 \pm 44$ days in the SES group vs $276 \pm 48$ days in the PES group, $\mathrm{P}=0.63$ ). In the $\mathrm{SES}$ group, there were 33 patients comprising 19 patients with acute coronary syndrome (ACS) and 14 with stable angina pectoris (SAP). In the PES group, there were 27 patients comprising 15 with ACS and 12 with SAP. The baseline characteristics of the patients are shown in Table 1 . There were no significant differences in the baseline characteristics between the 2 groups (Table 1).

\section{Angiographic Data}

About $50 \%$ of patients were implanted at the left descending artery in both stent groups [16 patients (48.5\%) in SES group, 14 patients $(51.1 \%)$ in PES group]. There was no significant difference of stent diameter and stent length between the 2 groups. Neither maximal inflation pressure nor balloon to artery ratio revealed a significant difference between the 2 groups (Table 2). Although there was no significant difference in pre-intervention and post-intervention QCA data, PES revealed a higher percentage DS and greater late loss than SES at 9 months after intervention. Mean follow-up DS was $6.6 \%$ in SES and $16.1 \%$ in PES $(\mathrm{P}=0.004)$. In the same manner, the mean late loss was $0.1 \mathrm{~mm}$ in the SES group and $0.5 \mathrm{~mm}$ in the PES group $(\mathrm{P}=0.001)$.

\section{OCT Findings}

In total, 13,762 struts in 1,496 mm single-stented segments were analyzed $(7,441$ struts in $762 \mathrm{~mm}$ in SES and 6,321 struts in $734 \mathrm{~mm}$ in PES). Overall, NIH thickness was $129 \pm 93 \mu \mathrm{m}$ and $\mathrm{NIH}$ area was $15.7 \pm 10.3 \%$. The overall rates of uncovered struts and malapposition were $9.1 \%$ and $2.1 \%$, respectively. In the SES group, the frequency of uncovered struts was $12.5 \pm 15.2 \%$ and in the case of the PES group, it 

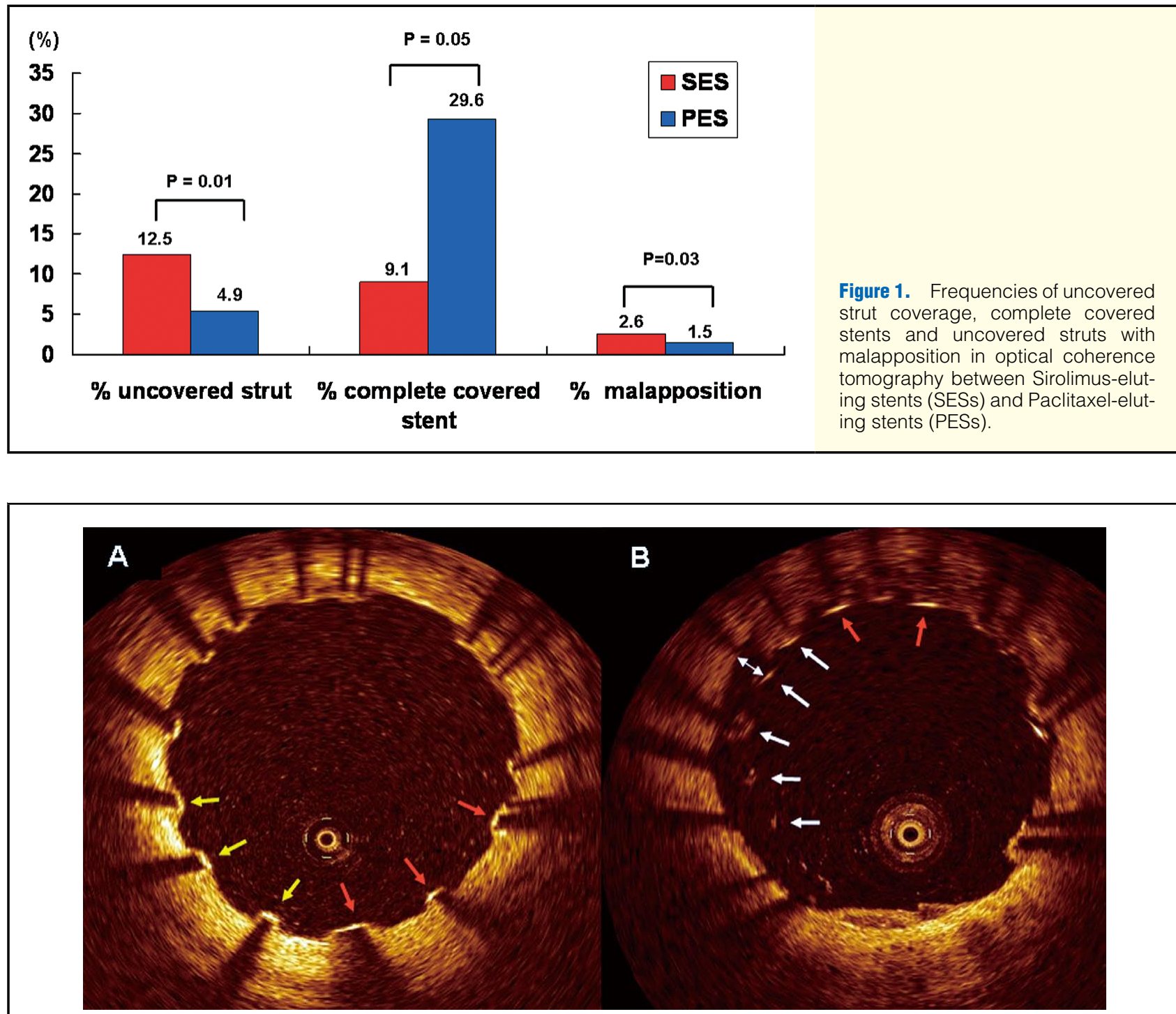

Figure 2. Comparison of optical coherence tomography (OCT) findings between (A) Sirolimus-eluting and (B) Paclitaxel-eluting stents. Uncovered struts without malapposition (red arrow), covered struts with thin neointima (yellow arrow) and uncovered struts with malapposition (white arrow) were observed in cross sectional OCT images.

\begin{tabular}{|lccc|}
\hline Table 3. Optical Coherence Tomographic Measurement & & \\
& SES $(\mathbf{n}=\mathbf{3 3})$ & PES $(\mathbf{n}=\mathbf{2 7})$ & P-value \\
No. of cross section & 715 & 701 & \\
Mean NIH thickness $(\mu \mathrm{m})$ & $86 \pm 53$ & $181 \pm 105$ & $<0.001$ \\
Mean stent area $\left(\mathrm{mm}^{2}\right)$ & $6.6 \pm 1.7$ & $7.6 \pm 1.9$ & 0.04 \\
Mean lumen area $\left(\mathrm{mm}^{2}\right)$ & $6.0 \pm 1.7$ & $6.0 \pm 1.6$ & 0.97 \\
Mean NIH area $\left(\mathrm{mm}^{2}\right)$ & $0.7 \pm 0.4$ & $1.6 \pm 1.0$ & $<0.001$ \\
$\%$ NIH area $(\%)$ & $11.2 \pm 7.2$ & $21.1 \pm 11.1$ & $<0.001$ \\
Cross section with uncovered struts & $278(38.9 \%)$ & $122(17.4 \%)$ & $<0.001$ \\
Cross section with malapposed struts & $95(13.3 \%)$ & $38(5.4 \%)$ & $<0.001$ \\
Cross section with uncovered struts $>0.3$ & $127(17.8 \%)$ & $62(8.8 \%)$ & $<0.001$ \\
Heterogeneity score & $1.6 \pm 0.5$ & $2.0 \pm 0.6$ & 0.01 \\
Presence of thrombi, $\mathrm{n}(\%)$ & $10(30.3 \%)$ & $5(18.5 \%)$ & 0.29 \\
\hline
\end{tabular}

SES, Sirolimus-eluting stent; PES, Paclitaxel-eluting stent; $\mathrm{NIH}$, neointimal hyperplasia.

The heterogeneity score of $\mathrm{NIH}$ thickness was generated by subtracting the minimal grade from the maximal grade. Cross sections with an uncovered strut ratio $>0.3$ was defined when the ratio of uncovered struts to total stent struts per cross section was more than 0.3.6 


\begin{tabular}{|c|c|c|c|}
\hline & ACS & SAP & P-value \\
\hline \multicolumn{4}{|l|}{ Total patients } \\
\hline $\mathrm{n}$ & 34 & 26 & \\
\hline No. of cross sections & 821 & 595 & \\
\hline Mean stent area $\left(\mathrm{mm}^{2}\right)$ & $7.0 \pm 12.0$ & $7.1 \pm 1.7$ & 0.73 \\
\hline Mean lumen area $\left(\mathrm{mm}^{2}\right)$ & $6.0 \pm 1.8$ & $5.9 \pm 1.5$ & 0.92 \\
\hline Mean neointimal thickness $(\mu \mathrm{m})$ & $116 \pm 88$ & $145 \pm 99$ & 0.24 \\
\hline Mean \% NIH (\%) & $14.6 \pm 10.4$ & $17.1 \pm 10.3$ & 0.36 \\
\hline Uncovered stent struts (\%) & $12.7 \pm 15.0$ & $4.4 \pm 7.5$ & 0.003 \\
\hline Cross sections with uncovered struts & $292(35.6 \%)$ & $108(18.2 \%)$ & $<0.001$ \\
\hline Cross sections with malapposed struts & $111(13.5 \%)$ & $22(3.7 \%)$ & $<0.001$ \\
\hline Cross sections with uncovered struts $>0.3$ & $140(17.1 \%)$ & $49(8.2 \%)$ & $<0.001$ \\
\hline Malapposed stent struts (\%) & $3.1 \pm 6.6$ & $0.8 \pm 2.5$ & 0.04 \\
\hline Heterogeneity score & $1.8 \pm 0.6$ & $1.7 \pm 0.5$ & 0.38 \\
\hline Presence of thrombi (\%) & $11(32.4 \%)$ & $4(15.4 \%)$ & 0.13 \\
\hline \multicolumn{4}{|l|}{ SES } \\
\hline $\mathrm{n}$ & 19 & 14 & \\
\hline No. of cross sections & 412 & 303 & \\
\hline Mean stent area $\left(\mathrm{mm}^{2}\right)$ & $6.4 \pm 1.7$ & $6.9 \pm 1.6$ & 0.35 \\
\hline Mean lumen area $\left(\mathrm{mm}^{2}\right)$ & $5.9 \pm 1.9$ & $6.1 \pm 1.6$ & 0.69 \\
\hline Mean neointimal thickness $(\mu \mathrm{m})$ & $72 \pm 59$ & $103 \pm 41$ & 0.10 \\
\hline Mean \% NIH (\%) & $9.7 \pm 8.1$ & $13.2 \pm 5.3$ & 0.17 \\
\hline Uncovered stent struts ( $\mathrm{n}, \%)$ & $18.2 \pm 17.4$ & $4.8 \pm 6.3$ & 0.002 \\
\hline Cross sections with uncovered struts & $214(51.9 \%)$ & $64(21.1 \%)$ & $<0.001$ \\
\hline Cross sections with malapposed struts & $84(20.4 \%)$ & $11(3.6 \%)$ & $<0.001$ \\
\hline Cross sections with uncovered struts $>0.3$ & $104(25.2 \%)$ & $23(7.6 \%)$ & $<0.001$ \\
\hline Malapposed stent struts (n, \%) & $4.2 \pm 7.8$ & $0.5 \pm 0.6$ & 0.06 \\
\hline Heterogeneity score & $1.6 \pm 0.5$ & $1.6 \pm 0.5$ & 0.72 \\
\hline Presence of thrombi (\%) & $7(36.8 \%)$ & $3(21.4 \%)$ & 0.34 \\
\hline \multicolumn{4}{|l|}{ PES } \\
\hline $\mathrm{n}$ & 15 & 12 & \\
\hline No. of cross sections & 409 & 292 & \\
\hline Mean stent area $\left(\mathrm{mm}^{2}\right)$ & $7.7 \pm 2.0$ & $7.4 \pm 1.8$ & 0.63 \\
\hline Mean lumen area $\left(\mathrm{mm}^{2}\right)$ & $6.2 \pm 1.7$ & $5.4 \pm 1.3$ & 0.53 \\
\hline Mean neointimal thickness $(\mu \mathrm{m})$ & $171 \pm 89$ & $194 \pm 125$ & 0.59 \\
\hline Mean \% NIH (\%) & $20.8 \pm 9.9$ & $21.6 \pm 12.9$ & 0.85 \\
\hline Uncovered stent struts ( $\mathrm{n}, \%)$ & $5.6 \pm 7.1$ & $4.0 \pm 9.0$ & 0.22 \\
\hline Cross sections with uncovered struts & $78(19.1 \%)$ & $44(15.1 \%)$ & 0.17 \\
\hline Cross sections with malapposed struts & $27(6.6 \%)$ & $11(3.8 \%)$ & 0.10 \\
\hline Cross sections with uncovered struts $>0.3$ & $36(8.8 \%)$ & $26(8.9 \%)$ & 0.96 \\
\hline Malapposed stent struts (n, \%) & $1.7 \pm 4.4$ & $1.2 \pm 3.7$ & 0.26 \\
\hline Heterogeneity score & $2.1 \pm 0.5$ & $1.8 \pm 0.6$ & 0.09 \\
\hline Presence of thrombi (\%) & $4(26.7 \%)$ & $1(8.3 \%)$ & 0.22 \\
\hline
\end{tabular}

ACS, acute coronary syndrome; SAP, stable angina pectoris; NIH, neointimal hyperplasia; SES, Sirolimus-eluting stent; PES, Paclitaxel-eluting stent.

was $4.9 \pm 7.9 \%(\mathrm{P}=0.01)$. The frequency of malapposition was $2.6 \pm 6.1 \%$ in SES and $1.5 \pm 4.0 \%$ in PES (P=0.03; Figure 1$)$. Although 9 months had passed after DES implantation, some of the stents showed uncovered and malapposed struts in both stent groups even after a 9-month follow-up (Figure 2). The number of complete covered stents with neointima was greater in PES [3 (9.1\%) in SES vs 8 (29.6\%) in PES, P=0.05] and stents without any malapposed strut were also more frequently observed in PES [12 (36.4\%) in SES vs 18 (66.7\%) in $\mathrm{PES}, \mathrm{P}=0.02]$.

Mean NIH thickness was thicker in PES than in SES $(86 \pm$ $53 \mu \mathrm{m}$ for SES vs $181 \pm 105 \mu \mathrm{m}$ for PES, $\mathrm{P}<0.001$; Table 3 ).
$\mathrm{NIH}$ area and percentage of NIH area were also significantly higher in the PES group $\left(0.7 \pm 0.4 \mathrm{~mm}^{2}\right.$ vs $1.6 \pm 1.0 \mathrm{~mm}^{2}$, $\mathrm{P}<0.001$ and $11.2 \pm 7.2 \%$ vs $21.1 \pm 11.1 \%, \mathrm{P}<0.001)$. These findings were compatible with the angiographic data, in which the late loss was greater in PES than in SES. The cross sections with uncovered and malapposed struts were detected more frequently in SES than in PES. The frequency of cross sections with an uncovered strut ratio $>0.3$ was also significantly higher in SES (Table 3). In the case of heterogeneity scores, PES revealed a higher value than SES with a significant difference (1.6 \pm 0.5 for SES vs $2.0 \pm 0.6$ for PES, $\mathrm{P}=0.01)$. Although statistical significance was not shown, 
intracoronary thrombi were frequently detected in SES [10 $(30.3 \%)$ in SES vs 5 (18.5\%) in PES, $\mathrm{P}=0.29$; Table 3].

Further statistical analysis was performed to determine the differences between ACS and SAP (Table 4). There was no significant difference in the NIH thickness and percentage of NIH area between ACS and SAP. However, ACS revealed a significantly higher rate of uncovered struts and malapposed struts than SAP $(12.7 \pm 15.0$ vs $4.4 \pm 7.5, \mathrm{P}=0.003$ and $3.1 \pm 6.6$ vs $0.8 \pm 2.5, \mathrm{P}=0.04)$. According to the type of stent, the incidence of uncovered and malapposed struts were different only in SES.

\section{Discussion}

In this study, the incidence of uncovered struts was significantly higher in SES than in PES at 9 months after stent implantation and the frequency of cross sections with an uncovered strut ratio $>0.3$ was significantly higher in SES, which was the best morphometric predictor for LST in a previous autopsy study. ${ }^{6}$ However, the pattern of neointima was more heterogeneous in PES. In addition, stent coverage was incomplete in both stent groups. Therefore, the present study suggests that the vascular healing pattern was somewhat different according to the type of DES, and dual antiplatelet therapy might be needed for more than 9 months in both SES and PES.

Sirolimus and Paclitaxel have many different properties. ${ }^{19}$ Sirolimus inhibits the G1 cell cycle and migration of vascular smooth muscle cells, whereas Paclitaxel inhibits the mitosis (M) phase of the cell cycle and leads to apoptotic cell death. ${ }^{20}$ Moreover, they have different diffusion capacities and distributions in the vascular wall. Sirolimus distributes equally within the vascular layers, whereas Paclitaxel accumulates in the adventitia. Accordingly, it is well known that SES and PES have different patterns of in-stent restenosis ${ }^{21,22}$ and different rates of angiographic restenosis and target vessel revascularization..$^{23,24}$ Corresponding with previous trials, the angiographic data of the present study revealed less late loss in the SES group. ${ }^{25,26}$ Coinciding with these findings in the OCT data, NIH thickness and percentage of NIH area were significantly lower in the SES group. Besides, several studies using IVUS or OCT have shown that stent type was an important factor of strut malapposition immediately after stent implantation. ${ }^{14,26}$ SES had a higher rate of malapposition than other DESs, which may be related to the strut thickness and stent design. ${ }^{14}$ Therefore, eluting drug, polymer, strut thickness and stent design may influence the different patterns of neointimal coverage and malapposition even after 9 months after stent implantation between SES and PES. Although PES revealed a higher rate of neointimal coverage in the present study, the incidence of LST has been known to be similar with SESs. ${ }^{27}$ Furthermore, a recent angioscopy study showed that neointimal coverage was more heterogeneous in PES than in SES and thrombi were more frequently observed in PES than in SES (43\% vs $19 \%, \mathrm{P}=0.04$ ). ${ }^{28}$ The present study used OCT and demonstrated a pattern of neointimal coverage that was more heterogeneous in PES than SES. These findings may imply that quantitative measurements of neointima and malapposition alone could not explain the whole mechanism of LST because the quality of functional neointima might be crucial to prevent the formation of thrombus and subsequent LST.

The rates of uncovered struts and malapposition were still considerable in both stent groups at 9 months after stent implantation (uncovered struts: $12.5 \pm 15.2 \%$ in SES vs
4.9 $\pm 7.9 \%$ in PES, $\mathrm{P}=0.01$, malapposition: $2.6 \pm 6.1 \%$ in SES vs $1.5 \pm 4.0 \%$ in PES, $\mathrm{P}=0.03$ ). According to previous data, the rates of uncovered struts were $15 \%, 11.1 \%$ and $5.7 \%$, respectively, in SES at the 3-, 6- and 12-month follow-up. ${ }^{11,29}$ In the present SES data, the rate of uncovered struts was $12.5 \%$, so the progression of endothelization after 3 months was detected indirectly and similar to the previous study at 6 months. However, because high rates of uncovered struts were still detected, the maintenance of dual anti-platelets over 9 months after implantation may be needed. According to clinical presentation, the vascular healing process regarding neointima coverage and stent apposition was delayed in ACS compared with SAP in the present study. Especially in SES, these differences were quite distinct, which might be also related to the innate characteristics of SES. ${ }^{30}$

Currently, there are limited data about microthrombi, which are incidentally observed in OCT imaging. The clinical significance of microthrombi should be elucidated via further clinical investigation. In the present study, the microthrombus was observed in 10 patients $(30.3 \%)$ in the SES group and 5 patients $(18.5 \%)$ in the PES group $(\mathrm{P}=0.29)$. Interestingly, recent OCT data showed that intracoronary microthrombi were more common in PES compared with SES. ${ }^{31}$ We could not clearly explain the reason why different results were obtained compared with the present study. Between the 2 studies, the stent platform was different as Taxus Express ${ }^{\circledR}$ was used in the previous study and Taxus Liberte $^{\circledR}$ was used in the present study. Therefore, intracoronary thrombus might be observed less in Taxus Liberte ${ }^{\circledR}$ than in Taxus Express ${ }^{\circledR}$ by a more homogeneous healing pattern because Taxus Liberte ${ }^{\circledR}$ has a thin strut and can deliver the drug more uniformly through the small cell area and reduce the circular cell diameter. However, the clinical implication of microthrombi still needs more cases and longer clinical follow-up because the number of enrolled patients in the present study was small.

\section{Study Limitations}

First, the present study was not randomized and the study population was small. Hence, there is a possibility of bias in this study. Second, OCT data before and immediately after stent implantation were not available. Third, the thickness of $\mathrm{NIH}$ measured does not reflect the fully functioning intact endothelium. Quality as well as quantity of NIH might be important to prevent thrombus formation, but the present study did not clarify the quantity of NIH and it might be difficult to investigate in a clinical situation. Fourth, although OCT has high resolution, more specific definition was applied that may not perfectly discriminate between thrombus and intracoronary tissue. Finally, there was no data for the relationship between clinical events and neointimal coverage detected by OCT. This data might be needed to evaluate the clinical implications of long-term clinical follow-up.

\section{Conclusions}

SES had a higher rate of uncovered and malapposed stent struts, but the pattern of neointimal coverage was more heterogeneous in PES. However, in both stent groups, the rates of uncovered struts were not negligible even at 9 months after implantation. In addition, this quantitative measurement of neointima and malapposition may not explain the whole mechanism of LST because the quality of functional neointima might be crucial to prevent the formation of thrombus and subsequent LST. Therefore, we could speculate that 
9 months duration of DAT in both SES and PES might not be sufficient. However, we need more data to determine the clinical relevance of neointima over stent detected by OCT and for qualitative evaluation of the neointima.

\section{Disclosure}

This study was partly supported by a grant from the Korea Healthcare technology R\&D Project, Ministry for Health, Welfare \& Family Affairs, Republic of Korea (No. A085012, A000385 and 0412-CR02-0704-0001), a grant from the Korea Health 21 R\&D Project, Ministry of Health \& Welfare, Republic of Korea (No. A085136) and the Cardiovascular Research Center, Seoul, Korea.

\section{References}

1. Eisenstein EL, Anstrom KJ, Kong DF, Shaw LK, Tuttle RH, Mark $\mathrm{DB}$, et al. Clopidogrel use and long-term clinical outcomes after drug-eluting stent implantation. JAMA 2007; 297: 159-168.

2. Salam AM, Al Suwaidi J, Holmes DR Jr. Drug-eluting coronary stents. Curr Probl Cardiol 2006; 31: 8-119.

3. Miyazawa A, Ako J, Hongo Y, Hur SH, Tsujino I, Courtney BK, et al. Comparison of vascular response to zotarolimus-eluting stent versus sirolimus-eluting stent: Intravascular ultrasound results from ENDEAVOR III. Am Heart J 2008; 155: 108-113.

4. Nakazawa G, Finn AV, John MC, Kolodgie FD, Virmani R. The significance of preclinical evaluation of sirolimus-, paclitaxel-, and zotarolimus-eluting stents. Am J Cardiol 2007; 100: 36M-44M.

5. Joner M, Nakazawa G, Finn AV, Quee SC, Coleman L, Acampado E, et al. Endothelial cell recovery between comparator polymerbased drug-eluting stents. J Am Coll Cardiol 2008; 52: 333-342.

6. Finn AV, Joner M, Nakazawa G, Kolodgie F, Newell J, John MC, et al. Pathological correlates of late drug-eluting stent thrombosis: Strut coverage as a marker of endothelialization. Circulation 2007 115: $2435-2441$

7. Regar E, Schaar JA, Mont E, Virmani R, Serruys PW. Optical coherence tomography. Cardiovasc Radiat Med 2003; 4: 198-204.

8. Yabushita H, Bouma BE, Houser SL, Aretz HT, Jang IK, Schlendorf $\mathrm{KH}$, et al. Characterization of human atherosclerosis by optical coherence tomography. Circulation 2002; 106: 1640-1605.

9. Jang IK, Bouma BE, Kang DH, Park SJ, Park SW, Seung KB, et al. Visualization of coronary atherosclerotic plaques in patients using optical coherence tomography: Comparison with intravascular ultrasound. J Am Coll Cardiol 2002; 39: 604-609.

10. Yamaguchi T, Terashima M, Akasaka T, Hayashi T, Mizuno K, Muramatsu T, et al. Safety and feasibility of an intravascular optical coherence tomography image wire system in the clinical setting. Am J Cardiol 2008; 101: 562-567.

11. Takano M, Inami S, Jang IK, Yamamoto M, Murakami D, Seimiya $\mathrm{K}$, et al. Evaluation by optical coherence tomography of neointimal coverage of sirolimus-eluting stent three months after implantation. Am J Cardiol 2007; 99: 1033-1038.

12. Honda Y. Drug-eluting stents. Insights from invasive imaging technologies. Circ J 2009; 73: 1371-1380.

13. Barlis P, Dimopoulos K, Tanigawa J, Dzielicka E, Ferrante G, Del Furia F, et al. Quantitative analysis of intracoronary optical coherence tomography measurements of stent strut apposition and tissue coverage. Int J Cardiol 2009 Jan 18 [Epub ahead of print].

14. Tanigawa J, Barlis P, Dimopoulos K, Dalby M, Moore P, Di Mario C. The influence of strut thickness and cell design on immediate apposition of drug-eluting stents assessed by optical coherence tomography. Int J Cardiol 2009; 134: 180-188.

15. Tanigawa J, Barlis P, Dimopoulos K, Di Mario C. Optical coherence tomography to assess malapposition in overlapping drugeluting stents. EuroInterv 2008; 3: 580-583.

16. Chen BX, Ma FY, Luo W, Ruan JH, Xie WL, Zhao XZ, et al. Neointimal coverage of bare-metal and sirolimus-eluting stents evaluated with optical coherence tomography. Heart 2008; 94: 566-570.

17. Kume T, Akasaka T, Kawamoto T, Ogasawara Y, Watanabe N, Toyota E, et al. Assessment of coronary arterial thrombus by optical coherence tomography. Am J Cardiol 2006; 97: 1713-1717.

18. Kim JS, Jang IK, Kim JS, Kim TH, Takano M, Kume T, et al. Optical coherence tomography evaluation of zotarolimus-eluting stents at 9 month follow up: Comparison with Sirolimus-eluting stents. Heart 2009; 95: 1907-1912.

19. Wessely R, Schomig A, Kastrati A. Sirolimus and Paclitaxel on polymer-based drug-eluting stents: Similar but different. J Am Coll Cardiol 2006; 47: 708-714.

20. Wang TH, Wang HS, Soong YK. Paclitaxel-induced cell death: Where the cell cycle and apoptosis come together. Cancer 2000; 88: $2619-2628$.

21. Colombo A, Orlic D, Stankovic G, Corvaja N, Spanos V, Montorfano M, et al. Preliminary observations regarding angiographic pattern of restenosis after rapamycin-eluting stent implantation. Circulation 2003; 107: 2178-2180.

22. Iakovou I, Schmidt T, Ge L, Sangiorgi GM, Stankovic G, Airoldi $\mathrm{F}$, et al. Angiographic patterns of restenosis after paclitaxel-eluting stent implantation. J Am Coll Cardiol 2005; 45: 805-806.

23. Dibra A, Kastrati A, Mehilli J, Pache J, Schuhlen H, von Beckerath $\mathrm{N}$, et al. Paclitaxel-eluting or sirolimus-eluting stents to prevent restenosis in diabetic patients. $N$ Engl J Med 2005; 353: 663-670.

24. Windecker S, Remondino A, Eberli FR, Juni P, Raber L, Wenaweser $\mathrm{P}$, et al. Sirolimus-eluting and paclitaxel-eluting stents for coronary revascularization. N Engl J Med 2005; 353: 653-662.

25. Morice MC, Colombo A, Meier B, Serruys P, Tamburino C, Guagliumi G, et al. Sirolimus- vs paclitaxel-eluting stents in de novo coronary artery lesions: The REALITY trial: A randomized controlled trial. JAMA 2006; 295: 895-904.

26. Rittersma SZ, de Winter RJ, Koch KT, Bax M, Schotborgh CE, Mulder KJ, et al. Impact of strut thickness on late luminal loss after coronary artery stent placement. Am J Cardiol 2004; 93: 477-480.

27. Buch AN, Waksman R. Cypher versus Taxus: All smoke and no fire: Lessons for future comparative drug-eluting stent trials in interventional cardiology. Am J Cardiol 2007; 99: 424-427.

28. Awata M, Nanto S, Uematsu M, Morozumi T, Watanabe T, Onishi $\mathrm{T}$, et al. Heterogeneous arterial healing in patients following paclitaxel-eluting stent implantation: comparison with sirolimus-eluting stents. JACC Cardiovasc Interv 2009; 2: 453-458.

29. Katoh H, Shite J, Shinke T, Matsumoto D, Tanino Y, Ogasawara $\mathrm{D}$, et al. Delayed neointimalization on sirolimus-eluting stents: 6month and 12-month follow up by optical coherence tomography. Circ J 2009; 73: $1033-1037$.

30. Kim JS, Fan C, Choi D, Jang IK, Lee JM, Kim TH, et al. Different patterns of neointimal coverage between acute coronary syndrome and stable angina after various types of drug-eluting stents implantation; 9-month follow-up optical coherence tomography study. Int $J$ Cardiol 2009 Aug 24 [Epub ahead of print].

31. Murakami D, Takano M, Yamamoto M, Inami S, Ohba T, Seino Y, et al. Advanced neointimal growth is not associated with a low risk of in-stent thrombus: Optical coherence tomographic findings after first-generation drug-eluting stent implantation. Circ J 2009; 73: $1627-1634$. 